\title{
Oral Microbiota, Periodontal Status, and Osteoporosis in Postmenopausal Females
}

Scarlette Hernández-Vigueras, ${ }^{*}$ Blanca Martínez-Garriga, ${ }^{\dagger}$ María Carmen Sánchez, ${ }^{\ddagger}$ Mariano Sanz, ${ }^{\dagger}$ Albert Estrugo-Devesa, $§$ Teresa Vinuesa, ${ }^{\dagger}$ José López-López,§ and Miguel Viñas ${ }^{\dagger} \|$

Background: Alterations in hormone levels during menopause decrease bone density and may worsen oral health, favoring the growth of periodontal pathogens, whose detection could improve the diagnosis of periodontitis. The aim of this study is to detect and quantify the main periodontal pathogens in the oral microbiota of postmenopausal females and to explore the relationship between clinical and periodontal parameters.

Methods: This was an observational cross-sectional study of 76 postmenopausal females. Dental examinations and sampling for microbiologic evaluation were performed, and a history of osteoporosis/osteopenia was collected. Real-time polymerase chain reaction was used for detecting and quantifying Fusobacterium nucleatum (Fn), Aggregatibacter actinomycetemcomitans (Aa), Porphyromonas gingivalis (Pg), Campylobacter rectus ( $\mathrm{Cr}$ ), and Tannerella forsythia (Tf). The results obtained were subjected to statistical analyses. Statistical significance was defined as $P<0.05$.

Results: Periodontitis was detected in $77.1 \%$ of females with osteoporosis/osteopenia $(P>0.05)$. A significant correlation was found between osteoporosis and missing teeth. $T$. forsythia and $\mathrm{C}$. rectus were detected in $100 \%$ of the samples, Fn and $\mathrm{Pg}$ in $98.7 \%$, and $\mathrm{Aa}$ in $73.7 \%$.

Conclusions: Osteoporosis did not influence the prevalence of periodontitis among postmenopausal females. The presence of periodontopathogenic bacteria was not sufficient to confirm disease. A preventive maintenance program for postmenopausal females, particularly osteoporotic females, who are at greater risk of tooth loss, could minimize the potential effects of bone loss on periodontal tissues. J Periodontol 2016;87:124-133.

\section{KEY WORDS}

Bacteria, anaerobic; oral health; osteoporosis Periodontal diseases; postmenopause; real-time polymerase chain reaction.

* Faculty of Medicine, Austral University of Chile, Valdivia, Chile.

$\uparrow$ Laboratory of Molecular Microbiology and Antimicrobials, Department of Pathology and Experimental Therapeutics, University of Barcelona, Hospitalet, Barcelona, Spain.

‡ Research Laboratory, Faculty of Dentistry, Complutense University of Madrid, Madrid, Spain.

$\S$ Section of Oral Medicine, Department of Odontostomatology, University of Barcelona, Barcelona, Spain.

\| CESPU (Cooperativa de Ensino Superior Politécnico e Universitário [Cooperative for Higher, Polytechnic and University Education]), IINFACTS (Instituto de Investigação e Formação Avançada em Ciências e Tecnologias da Saúde [Institute of Research and Advanced Training in Health Sciences and Technologies]), Gandra, Portugal.
$M$ enopause is the permanent cessation of menstrual periods, whether naturally or induced by surgery, chemotherapy, or radiation. It is accompanied by hormonal changes, most prominently decreases in estrogen and androgen levels, which produce a variety of signs and symptoms: 1) vasomotor symptoms; 2) decreased bone density; 3) hot flashes; 4) profuse perspiration; 5) atrophic vaginitis; and 6 ) oral cavity alterations. ${ }^{1}$

The oral symptoms during menopause include dry mouth (xerostomia), burning mouth, and changes in taste perception and are a common complaint of postmenopausal females. ${ }^{2}$ If xerostomia is left untreated, it may change the oral $\mathrm{pH}$ and increase the risk of developing oral diseases. These symptoms have been attributed to reduced salivary flow, and oral pathologies seem to be affected by changes in salivary and gingival crevicular fluid (GCF) composition. ${ }^{3}$ Saliva contributes to maintenance of the oral $\mathrm{pH}$ by neutralizing acids from food and beverages, as well as from bacterial activity, thereby reducing the risk of periodontal disease. ${ }^{3}$ After menopause, reduced salivary flow rate and low $\mathrm{pH}$ may make females more prone to oral health problems. ${ }^{4}$ Decreased estrogen levels, in addition to worsening periodontal conditions, increase the risk of osteoporosis in postmenopausal females. ${ }^{3}$ Osteoporosis is a systemic skeletal disease characterized by a generalized and progressive loss of bone mineral density (BMD) and an 
increased propensity to fracture. ${ }^{5,6}$ Its prevalence increases with age, and it affects all bones of the body, including the jaw bone, resulting in cortical thinning and a reduction of cancellous bone. ${ }^{6}$

For females, in addition to age, the menopausal transition itself causes a period of rapid bone loss $(12 \%$ to $20 \%$ in the first 5 years after menopause) such that the risk of fracture in postmenopausal females is higher than in males of the same age. ${ }^{7}$

The changes in bone composition also have implications for oral health, ${ }^{8}$ including the risk of enhanced progression of periodontitis. ${ }^{5,6}$ Thus, bone loss is a feature shared by periodontal disease and osteoporosis. The relationship between the skeletal loss of $\mathrm{BMD}$ and the increased periodontal bone loss has been ascribed to several factors. ${ }^{5}$ Greater periodontal bone loss may occur simply because the bone surrounding the teeth is less dense and therefore less resistant to resorption. ${ }^{5}$ In addition, the loss of alveolar BMD may leave bone more susceptible to periodontal bacteria, increasing the risk for periodontitis and tooth loss. ${ }^{9}$

Osteoporotic females show greater clinical attachment loss and gingival recession than females with a normal BMD, which suggests a greater severity of periodontitis. ${ }^{10}$ The early diagnosis of reduced $B M D$, before the establishment of a significant negative influence on the periodontal tissues, has been recommended. ${ }^{9}$

The pathogenic microbial population involved in periodontitis is highly complex. However, the literature contains reports of associations among periodontal disease and certain microorganisms, such as Aggregatibacter actinomycetemcomitans (Aa), Prevotella intermedia ( $P i)$, Porphyromonas gingivalis $(\mathrm{Pg})$, Campylobacter rectus $(\mathrm{Cr})$, Treponema denticola, Fusobacterium nucleatum (Fn), and Tannerella forsythia $(T f) .{ }^{11,12} \mathrm{~A}$ quantitative analysis of these periodontal pathogens could improve both the diagnosis and evaluation of periodontitis and the understanding of its relationship to osteoporosis.

The aim of this study is to detect and quantify the main periodontal pathogens in the oral microbiota of postmenopausal females to explore the relation between the microbiota and clinical and periodontal parameters. The measurement of $\mathrm{pH}$ was done as a general parameter because it is related strongly with consumption of sugar and acidic beverages, xerostomia, and oral microbiota. ${ }^{3}$

\section{MATERIALS AND METHODS}

\section{Study Population}

This is an observational cross-sectional study of 76 postmenopausal females who were treated at the Dental Hospital of the University of Barcelona, Barcelona, Spain. Dental examinations and sampling for microbiologic evaluation were performed between May 2009 and September 2012.

The study population was selected from $694 \mathrm{fe}$ males who participated in a questionnaire related to fracture risk factors in the Rheumatology Service of the University Hospital of Bellvitge, Hospitalet, Barcelona, Spain, in 1999. Only 137 of the 427 females who could be contacted agreed to participate. Subgingival samples were collected from 76 of these females, who were finally included in the study (aged 40 to 71 years; median age: 63 years). None of them were under specific estrogen replacement treatment.

The study was approved by the Ethical Committee of the Faculty of Dentistry, University of Barcelona. The study was conducted in accordance with the Declaration of Helsinki of 1975 (revised in 2013). All of the patients were informed about the objectives and methodology and provided written informed consent to participate in the study.

\section{Oral Examination}

All of the participants received a complete oral examination. The following variables were assessed: 1) number of missing teeth, not including third molars (28 maximum); 2) probing depth (PD), assessed with a World Health Organization (WHO) probe in all teeth; 3) oral hygiene status, determined according to the criteria of the index of Greene and Vermillion; ${ }^{13}$ 4 ) the carious, absent, and obturated teeth (CAOD) index, which was obtained by summing carious, missing, and obturated teeth and dividing by the total number of teeth; 5) the presence of mucosal injury; 6) periodontal treatment needs, examined by using the Community Periodontal Index of Treatment Needs recommended by the WHO; 7) oral $\mathrm{pH}$, measured by using $\mathrm{pH}$ indicator strips that were placed on the floor of the mouth; and 8) xerostomia, determined by using a specific questionnaire and performing the test of the mirror (sticking of a dental mirror to the buccal mucosa was taken as a positive result for xerostomia).

\section{Diagnosis of Osteoporosis/Osteopenia}

Osteopenia was assessed from densitometry reports. The methods and criteria used in the diagnosis of osteoporosis were those established by the WHO. ${ }^{14}$ According to these criteria, osteoporosis is defined as $\mathrm{BMD} \geq 2.5$ standard deviations (SDs) below the average value for young healthy females ( $T$ score $\leq 2.5$ SDs), and osteopenia is defined as 1 to 2.5 SDs ( $T$ score between -1.0 and -2.5 SDs). Association between osteopenia and oral bone loss and between osteopenia and oral state were accomplished as recommended in the literature. ${ }^{15,16}$

II Merck, Darmstadt, Germany 


\section{Diagnosis of Periodontitis}

Females were considered to have periodontitis if they met the criteria established by the American Academy of Periodontology, which state that the patient must have at least one site with PD and clinical attachment level $\geq 4 \mathrm{~mm}^{17}$

\section{Specimen Collection}

Subgingival samples were taken after supragingival plaque removal. Two paper points (size 30) ${ }^{\#}$ were inserted in the deepest periodontal pocket for $20 \mathrm{sec}-$ onds and placed in labeled sterile test tubes containing $500 \mu \mathrm{L}$ bidistilled water. The vials were immediately frozen at $-80^{\circ} \mathrm{C}$. Despite the limitation derived from the sampling of only one pocket, the samples were harvested from the deepest one, because deeper pockets offer a better environment for anaerobes and are useful as a general parameter.

\section{Reference Bacterial Strains}

Standard reference strains of Fn DMSZ 20482, Aa DSMZ 8,324, Pg ATCC 33277, Cr ATCC 33238, and Tf ATCC 43037 were used.

\section{DNA Extraction}

The tubes containing the paper points were thawed, vortexed for 2 to 3 minutes, and then centrifuged at $14,000 \mathrm{rpm}$ for 10 minutes. The pellet was processed with a commercial DNA extraction kit** following the protocol of the manufacturer for Gram-negative bacteria. DNA purity and concentrations were determined spectrophotometrically using a spectrophotometer. ${ }^{\dagger \dagger}$ DNA from the controls (reference bacterial strains) was obtained using the same method. Purified genomic DNA of $\mathrm{Pg}, \mathrm{Aa}, \mathrm{Tf}, \mathrm{Cr}$, and $\mathrm{Fn}$ was obtained from $1 \mathrm{~mL}$ viable bacteria containing $10^{8}, 10^{9}, 10^{8}, 10^{6}$, and $10^{6}$ colony forming units (CFU)/mL, respectively. Tenfold serial dilutions of each DNA were prepared in sterile water. ${ }^{\ddagger}$ All DNA samples were frozen at $-20^{\circ} \mathrm{C}$ until used.

\section{Quantitative Real-Time Polymerase Chain Reaction}

Primers and probes. The primers $§ \S$ and probes ${ }^{|l| \mid}$ sequences used to target the $16 \mathrm{~S}$ ribosomal ribonucleic acid (rRNA) gene are listed in Table $1 .{ }^{18,19}$ The oligonucleotide probes were labeled at the $5^{\prime}$ end with fluorescent 6-carboxyfluorescein and at the $3^{\prime}$ end with 6-carboxytetramethylrhodamine.

Quantitative real-time polymerase chain reaction conditions. Polymerase chain reaction (PCR) amplification was performed in a total reaction mixture volume of $10 \mu \mathrm{L}$, containing $8 \mu \mathrm{L}$ of $2 \times$ master mixture If and $2 \mu \mathrm{L}$ DNA from the samples. Each DNA sample was analyzed in duplicate. The no template control (NTC) consisted of $8 \mu \mathrm{L}$ master mixture without DNA. The samples were placed in white 384-well plates $^{\# \#}$ and subjected to an initial amplification cycle of $95^{\circ} \mathrm{C}$ for 10 minutes, followed by 40 cycles at $95^{\circ} \mathrm{C}$ for 15 seconds and $60^{\circ} \mathrm{C}$ for 1 minute in a thermocycler. *** To avoid carryover DNA, the laboratory was separated into pre-PCR and post-PCR areas, and strict barrier measures were used. However, none of these methods prevented the amplification of unspecific bacteria in some of the NTCs.

Data analyses. Quantification cycle $(\mathrm{Cq})$ values were determined using a software package. ${ }^{\dagger \dagger}$

Quantitation of the DNA samples was based on accurate standard curves for each bacterium in each run, using appropriate external standards of known concentration. Standard curves were constructed by plotting the $\mathrm{Cq}$ values generated from the quantitative PCR (qPCR) against $\mathrm{Pg}, \mathrm{Tf}, \mathrm{Cr}, \mathrm{Fn}$, and $\mathrm{Aa}$ (see supplementary Figures 1 through 5 in online Journal of Periodontology) and total cell concentrations (log $\mathrm{CF}(/ \mathrm{mL})$. The correlation between $\mathrm{Cq}$ values and $\mathrm{CFU} / \mathrm{mL}$ was automatically generated.

All assays were developed with a linear quantitative detection range established by a slope of 3.2 to 3.7 cycles/log decade, $r^{2}>0.994$ and an efficiency range of 1.8 to 2.0. The limit of detection was calculated using the $\mathrm{Cq}$ value from the last point on the standard curve that differed by 3 units from the lowest $\mathrm{Cq}$ value of the NTC. Values below this detection range may be detectable, but they are not quantifiable. Samples were considered positive when the $\mathrm{Cq}$ values were above the detection limit.

\section{Statistical Analyses}

A descriptive statistical analysis was performed based on the mean or median according to normality criteria (Kolmogorov-Smirnov test) and the SD or interquartile range (IQR), respectively. A bivariate analysis was performed using the $\chi^{2}$ test for the comparison of qualitative variables. Student $t$ test, analysis of variance, the Mann-Whitney $U$ test, or the Kruskal-Wallis test for quantitative variables was used according to normality criteria and number of categories studied. Pearson or Spearman correlation tests were used to compare quantitative variables when appropriate. A multivariate analysis using binary logistic regression was conducted to determine the association between osteoporosis and periodontitis. The statistical significance of the two-way interactions between BMD and other variables in the main effects model was assessed using forward stepwise regression

\# DENTSPLY Maillefer, Ballaigues, Switzerland

** DNeasy blood and tissue kit, Qiagen, Hilden, Germany.

$\dagger$ NanoDrop 1000 spectrophotometer, Thermo Fisher Scientific, Waltham, MA.

† PCR grade water, Roche Diagnostics, Mannheim, Germany.

$\S \S$ Thermo Fisher Scientific.

III Thermo Fisher Scientific.

II LightCycler 480 Probes Master, Roche Diagnostics.

\#\# LightCycler 480 Multiwell Plate 384, Roche Diagnostics.

*** LightCycler 480 II, Roche Diagnostics.

$\dagger \dagger \dagger$ LightCycler 480 Software v.1.5, Roche Diagnostics. 
Table I.

\section{Primers and Probes Used for Quantification of Genomic DNA From the Target Bacteria}

\begin{tabular}{|c|c|c|c|}
\hline Sequence $\left(5^{\prime}-3^{\prime}\right)$ & Concentration (nM) & Target gene & Reference \\
\hline $\begin{array}{l}\text { Aa } \\
\text { Forward, GAA CCT TAC CTA CTC TTG } \\
\text { ACA TCC GAA } \\
\text { Reverse, TGC AGC ACC TGT CTC AAA GC } \\
\text { Probe, AGA ACT CAG AGA TGG GTT TGT } \\
\text { GCC TTA GGG }\end{array}$ & $\begin{array}{l}\text { Primers, } 300 \\
\text { Probe, } 100\end{array}$ & I6S rRNA (80 bp) & Boutaga et al. ${ }^{18}$ \\
\hline $\begin{array}{l}\text { Pg } \\
\text { Forward, GCG CTC AAC GTT CAG CC } \\
\text { Reverse, CAC GAA TTC CGC CTG C } \\
\text { Probe, CAC TGA ACT CAA GCC CGG } \\
\text { CAG TIT CAA }\end{array}$ & $\begin{array}{l}\text { Primers, } 300 \\
\text { Probe, } 300\end{array}$ & I 6S rRNA (67 bp) & Boutaga et al. ${ }^{18}$ \\
\hline $\begin{array}{l}\text { Cr } \\
\text { Forward, TIT CGG AGC GTA AAC TCC } \\
\text { TIT TC } \\
\text { Reverse, CGC TTG CAC CCT CCG TAT } \\
\text { Probe, TCC GTG CCA GCA GCC GC }\end{array}$ & $\begin{array}{l}\text { Primers, } 900 \\
\text { Probe, } 100\end{array}$ & I6S rRNA & Figuero et al. ${ }^{19}$ \\
\hline $\begin{array}{l}\text { Tf } \\
\text { Forward, GGG TGA GTA ACG CGT ATG } \\
\text { TAA CCT } \\
\text { Reverse, ACC CAT CCG CAA CCA ATA AA } \\
\text { Probe, CCC GCA ACA GAG GGA TAA CCC } \\
\text { GG }\end{array}$ & $\begin{array}{l}\text { Primers, } 300 \\
\text { Probe, } 200\end{array}$ & I6S rRNA & Boutaga et al. ${ }^{18}$ \\
\hline $\begin{array}{l}\text { Fn } \\
\text { Forward, GGA TIT ATT GGG CGT AAA GC } \\
\text { Reverse, GGC ATT CCT ACA AAT ATC TAC } \\
\text { GAA } \\
\text { Probe, CTC TAC ACT TGT AGT TCC G }\end{array}$ & $\begin{array}{l}\text { Primers, } 600 \\
\text { Probe, } 300\end{array}$ & I6S rRNA (I62 bp) & Boutaga et al. ${ }^{18}$ \\
\hline
\end{tabular}

Primers and probes targeted the $16 \mathrm{~S}$ rRNA gene.

to test whether other variables modified the effect of BMD on periodontitis. To select the most accurate model, the area under the curve of each model was analyzed according to the receiving operating characteristics curves. A statistical package ${ }^{\neq \neq}$was used for all statistical analyses. Statistical significance was defined as $P<0.05$.

\section{RESULTS}

The general characteristics and relevant variables regarding the oral health status of the 76 females who participated in the study are listed in Table 2. For some females, the data were incomplete because they could not attend all sessions of data collection. All participants were kept in the analysis because the percentage of missing data was $<10 \%$ of the total for all variables.

The participants had a median age of 63.0 years $(\mathrm{IQR}=2)$. Periodontitis was detected in $47.9 \%$ of the patients, and $41.1 \%$ required periodontal treatment. Most (78.6\%) had been diagnosed previously with osteopenia or osteoporosis.
Table 3 provides a cross-tabulation of periodontal disease versus osteoporosis, age, number of missing teeth, oral $\mathrm{pH}$, CAOD index, need for treatment, oral hygiene, xerostomia, and mucosal injury. Periodontitis was detected in $22.9 \%$ of the females with no previous diagnosis of osteopenia/osteoporosis, in $57.1 \%$ of the females with osteopenia, and in $20 \%$ of those with osteoporosis, although there was no association between osteoporosis/osteopenia and periodontitis $(P=$ $0.52)$. There was a significant correlation between periodontitis and oral hygiene $(P=0.003)$ and between periodontitis and the need for treatment $(P=0.001)$. The associations between periodontitis and missing teeth and between periodontitis and xerostomia were not significant $(P=0.12$ and $P=0.10$, respectively).

An analysis of the correlation among osteoporosis and the same clinical variables (data not shown) showed that, among the two groups (normal/osteopenia and osteoporosis), only the relation to the number of missing teeth was significant $(P<0.05)$.

玤 SPSS v.17.0 for Windows, IBM, Chicago, IL. 
Table 2.

\section{Characteristics of the Patients $(n=76)$}

\begin{tabular}{|c|c|}
\hline Variable & Value \\
\hline Age (years), median (IQR) & $63.00(2.00)$ \\
\hline Missing teeth, median (IQR) & $5.00(8.75)$ \\
\hline CAOD index, mean (SD) & $|7.2|(8.00)$ \\
\hline $\begin{array}{l}\text { Treatment need, n (\%)* } \\
\text { No } \\
\text { Profound hygiene } \\
\text { Periodontal treatment }\end{array}$ & $\begin{array}{c}5(6.8) \\
38(52.1) \\
30(41.1)\end{array}$ \\
\hline $\begin{array}{l}\text { Periodontitis, n (\%)* } \\
\text { Negative } \\
\text { Positive }\end{array}$ & $\begin{array}{l}38(52.1) \\
35(47.9)\end{array}$ \\
\hline $\begin{array}{l}\text { Mucosal injury, n (\%)* } \\
\text { No } \\
\text { Yes }\end{array}$ & $\begin{array}{l}45(61.6) \\
28(38.4)\end{array}$ \\
\hline $\begin{array}{l}\text { Xerostomia, n (\%)* } \\
\text { No } \\
\text { Yes }\end{array}$ & $\begin{array}{c}67(91.8) \\
6(8.2)\end{array}$ \\
\hline $\mathrm{pH}$, median (IQR) & $7.0(1.0)$ \\
\hline $\begin{array}{l}\mathrm{pH}, \mathrm{n}(\%) * \\
\text { Basic }(>7) \\
\text { Neutral }(6.5 \text { to } 7) \\
\text { Acid }(<6.5)\end{array}$ & $\begin{array}{ll}14 & (20.3) \\
27 & (39.1) \\
28 & (40.6)\end{array}$ \\
\hline $\begin{array}{l}\text { Oral hygiene, n (\%)* } \\
\text { Good } \\
\text { Regular } \\
\text { Bad }\end{array}$ & $\begin{array}{l}24(32.9) \\
32(43.8) \\
17(23.3)\end{array}$ \\
\hline $\begin{array}{l}\text { Osteoporosis, n (\%)* } \\
\text { No } \\
\text { Osteopenia } \\
\text { Osteoporosis }\end{array}$ & $\begin{array}{l}16(21.3) \\
40(53.3) \\
19(25.3)\end{array}$ \\
\hline
\end{tabular}

* Information missing for some patients.

The most prevalent bacteria were $T f$ and $\mathrm{Cr}$, which were detected in $100 \%$ of the samples, followed by Fn and $\mathrm{Pg}$ (98.7\% in both cases) and $\mathrm{Aa}(73.7 \%)$. It should be highlighted that, in all cases but $P g$, it was feasible to quantify bacteria when present. $P g$ was quantifiable in only $84.2 \%$ of the samples, because in $14.5 \%$ the value was below the minimum needed to quantify. Quantification of periodontal bacteria according to the presence or absence of periodontitis is reported in Table 4.

The box plot in Figure 1A shows the distribution of the five periodontal bacteria according to the presence or absence of periodontitis; the differences were statistically non-significant $(P>0.05)$. The box plot in Figure 1B shows the distribution of bacteria in osteo- porotic, osteopenic, and normal patients. Again, the differences between the groups were not significant $(P>0.05)$.

Scatter plots were used to analyze the relationship between the periodontal pathogens $\mathrm{Fn}, \mathrm{Tf}, \mathrm{Cr}, \mathrm{Pg}$, and $A a$, and non-parametric Spearman correlation coefficients were calculated (Table 5). Statistically significant positive relationships were found between log $\mathrm{Cr}$ and $\log \mathrm{Fn}(r=0.815, P<0.001)$ and $\log \mathrm{Tf}$ and $\log$ Fn $(r=0.510, P<0.001)$. Other significant relationships among bacteria included a moderately positive relationship between $\log P g$ and $\log T f(r=0.410, P<0.001)$ and slightly positive relationship between log $T f$ and $\log C r(r=0.381, P=0.001), \log P g$ and $\log C r(r=0.328$, $P=0.004), \log P g$ and $\log F n(r=0.268, P=0.02)$, and $\log A a$ and $\log T f(r=0.273, P=0.04)$.

Spearman correlation was used to compare periodontal pathogens and oral parameters. A significant highly positive relationship was found between missing teeth and CAOD index $(r=0.770, P<0.001)$ and a slightly positive relation between $\log \mathrm{Pg}$ and $\mathrm{pH}$ $(r=0.285, P=0.02)$.

Analysis of the associations between clinical variables and $\mathrm{pH}$ values (data not shown) failed to demonstrate a significant correlation between oral hygiene and $\mathrm{pH}(P=0.50)$. Only the differences among basic, neutral, and acidic $\mathrm{pH}$ groups and the $\log \mathrm{CFU} / \mathrm{mL}$ of $A$ a were significant $(P=0.01)$. For $P g$, the $P$ value was 0.053 .

\section{DISCUSSION}

According to the present findings, the presence of osteoporosis/osteopenia does not influence the prevalence of periodontitis among postmenopausal females. The criteria for the diagnosis of periodontitis were clinical examination parameters. In a systematic review by Martínez-Maestre et al., ${ }^{20}$ five of nine studies based on the same criteria concluded that the correlations between osteoporosis and periodontitis were negative. In contrast, in most of the studies based on maxillary radiologic criteria, a positive association was determined. Martínez-Maestre et al. ${ }^{20}$ highlighted the need for well-controlled studies to better determine the complexity of this relationship.

The results of two recent studies performed on samples from postmenopausal females also reached conflicting conclusions, thus adding to the current controversy and emphasizing the need for greater uniformity in the methodologies to study the relationship between osteoporosis and periodontitis. ${ }^{21,22}$ Methodologic limitations include small sample sizes, non-comparable study populations, and the diverse criteria used to define osteoporosis and periodontitis.

Although there was no correlation between both diseases, when the patients were evaluated in groups 
Table 3.

\section{Correlation Among Periodontitis and Clinical and Oral Variables}

\begin{tabular}{|c|c|c|c|c|}
\hline \multirow[b]{2}{*}{ Variable } & \multicolumn{2}{|c|}{ Periodontitis } & \multirow[b]{2}{*}{ Total } & \multirow[b]{2}{*}{$P$} \\
\hline & Negative & Positive & & \\
\hline Osteoporosis, n (\%) & & & & 0.52 \\
\hline No & $8(21.1)$ & $8(22.9)$ & $16(21.9)$ & \\
\hline Osteopenia & $18(47.4)$ & $20(57.1)$ & $38(52.1)$ & \\
\hline Osteoporosis & $12(31.6)$ & $7(20.0)$ & $19(26.0)$ & \\
\hline Age (years), median (IQR) & $62.5(3.0)$ & $63.0(2.0)$ & $63.0(2.0)$ & 0.62 \\
\hline Age (years), n (\%) & & & & 0.42 \\
\hline$\leq 60$ & $2(5.3)$ & $4(11.4)$ & $6(8.2)$ & \\
\hline$>60$ & $36(94.7)$ & $31(88.6)$ & $67(91.8)$ & \\
\hline Missing teeth, median (IQR) & $4.0(6.0)$ & $7.0(13.0)$ & $5.0(8.75)$ & 0.12 \\
\hline $\mathrm{pH}, \mathrm{n}(\%)$ & & & & 0.55 \\
\hline Basic & $7(19.4)$ & $7(21.9)$ & $14(20.6)$ & \\
\hline Neutral & $12(33.3)$ & $14(43.8)$ & $26(38.2)$ & \\
\hline Acid & $17(47.2)$ & II (34.4) & $28(41.2)$ & \\
\hline CAOD index, mean (SD) & $16.53(7.47)$ & $17.94(8.60)$ & $17.21(8.00)$ & 0.45 \\
\hline $\mathrm{pH}$, median (IQR) & $7.0(1.0)$ & $7.0(1.0)$ & $7.2(1.0)$ & 0.32 \\
\hline Treatment need, n (\%) & & & & 0.001 \\
\hline No & $4(10.5)$ & I (2.9) & $5(6.8)$ & \\
\hline Profound hygiene & $26(68.4)$ & $12(34.3)$ & $38(52.1)$ & \\
\hline Periodontal treatment & $8(21.1)$ & $22(62.9)$ & $30(41.1)$ & \\
\hline Oral hygiene, n (\%) & & & & 0.003 \\
\hline Good & $19(50.0)$ & $5(14.3)$ & $24(32.9)$ & \\
\hline Regular & $14(36.8)$ & $18(51.4)$ & $32(43.8)$ & \\
\hline Bad & $5(13.2)$ & $12(34.3)$ & $17(23.3)$ & \\
\hline Xerostomia, n (\%) & & & & 0.10 \\
\hline No & $37(97.4)$ & 30 (85.7) & $67(91.8)$ & \\
\hline Yes & I (2.6) & $5(14.3)$ & $6(8.2)$ & \\
\hline Mucosal injury, n (\%) & & & & 0.22 \\
\hline No & $26(68.4)$ & $19(54.3)$ & $45(61.6)$ & \\
\hline Yes & $12(31.6)$ & $16(45.7)$ & $28(38.4)$ & \\
\hline
\end{tabular}

Numbers in bold represent statistical significance $(P<0.05)$.

of normal/osteopenia and osteoporosis, significant differences were found with respect to the number of missing teeth. The associations between dental status and skeletal bone density in healthy postmenopausal females have been investigated previously. Some findings support the hypothesis that systemic bone loss contributes to tooth loss. ${ }^{23}$

Tooth loss is considered the ultimate outcome of periodontal disease. ${ }^{24}$ The chronic inflammation triggered by the bacteria that cause periodontal disease underlies both breakdown of the jaw bone and tooth loss. Tezal et al. ${ }^{25}$ reported that periodontal disease is a strong and independent predictor of tooth loss in postmenopausal females. However, in the patients in the present study, a relationship between periodontitis and missing teeth could not be established. One explanation for the different findings is that patients with chronic periodontitis $(\mathrm{CP})$ undergoing therapy may have lower rates of tooth loss. ${ }^{26-28}$ For example, the systemic statins frequently used in lipid-lowering therapies have an anti-inflammatory effect on periodontal disease and protect against tooth loss. ${ }^{29}$ Higher rates of tooth loss have also been associated with low socioeconomic status, a low level of education, and low income and with age and smoking habits. ${ }^{30}$ However, this information was not collected from the participants in the present study. The results showed that, in the present patients, periodontitis was correlated with the level of oral hygiene. Therefore, the potential effects of osteoporotic factors on the periodontal tissues could 
Table 4.

Quantification of Subgingival Pg, Tf, Cr, Fn, and Aa in the Total Study Sample ( $\mathrm{N}=76)$

\begin{tabular}{lcccc}
\hline & \multicolumn{2}{c}{ Periodontitis, median (IQR) } & & \\
\cline { 2 - 3 } Variable & Negative $(n=38)$ & Positive $(n=35)$ & Total, median (IQR) & $P$ \\
\hline Log Pg & $3.03(2.30)$ & $3.40(2.49)$ & $3.00(2.56)$ & 0.53 \\
Log Tf & $4.86(1.86)$ & $5.25(1.67)$ & $5.09(1.75)$ & 0.08 \\
$\log C r$ & $5.25(1.04)$ & $5.42(1.29)$ & $5.40(1.19)$ & 0.59 \\
$\log F n$ & $6.31(0.81)$ & $6.26(0.84)$ & 0.46 \\
Log Aa & $6.23(0.84)$ & $2.72(3.21)$ & $2.50(1.94)$ & 0.09 \\
\hline
\end{tabular}

A

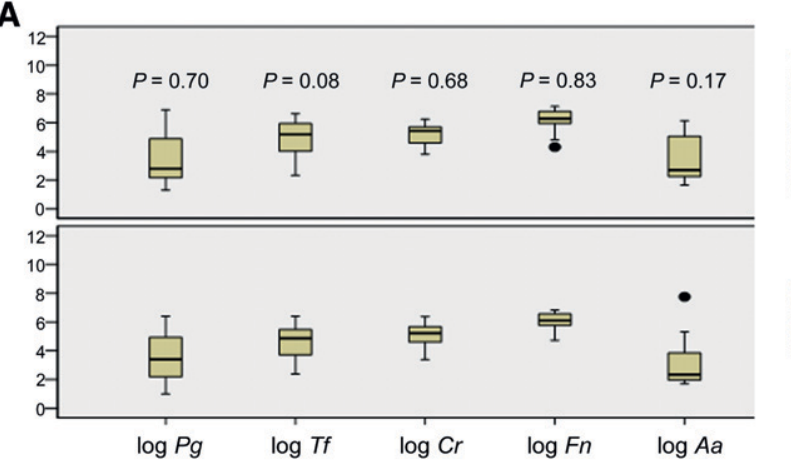

B

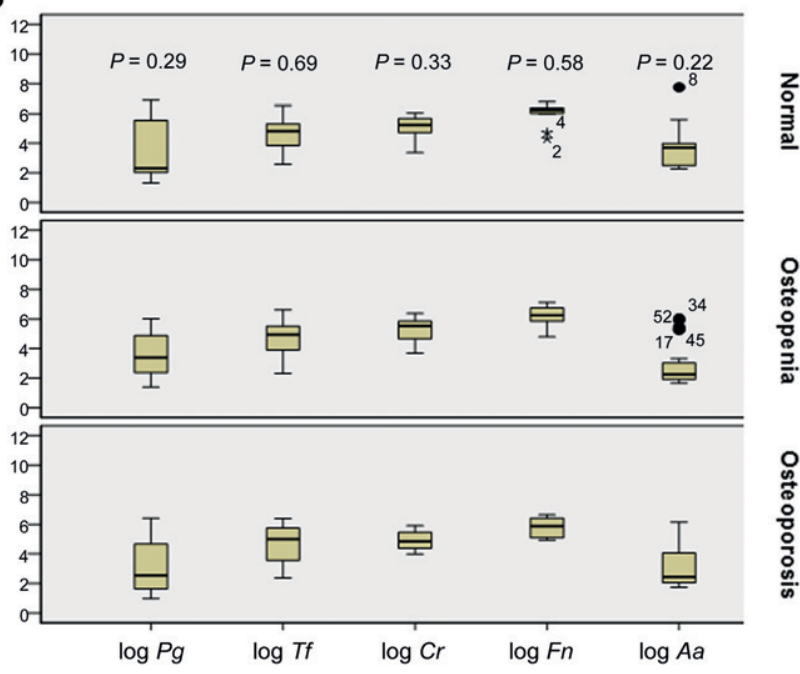

Figure I.

A) Box plot of normal patients and the periodontitis group and quantification of periodontal bacteria. B) Box plot of normal, osteopenic, or osteoporotic patients and quantification of periodontal bacteria.

be minimized by combining good oral hygiene with regular check-ups.

The association between periodontitis and xerostomia was not significant, but a positive trend was evident because five of the six females with dry-mouth symptoms were diagnosed with periodontitis. More patients with xerostomia are required to better analyze this relationship. Salivary flow rates are lower in postmenopausal females, although hormone therapy has been shown to improve saliva production. ${ }^{31-32}$

In this study, qPCR assays are used successfully to determine the abundance of periodontal pathogens known to be associated with the progression and severity of periodontal disease in paper-point samples collected from postmenopausal females. The samples were harvested only from the deepest pocket, because deeper pockets offer a better environment for anaerobes and, consequently, their more extensive colonization and are useful as a general parameter. The prevalences of four of the five periodontal bacteria analyzed $(\mathrm{Pg}, \mathrm{Tf}, \mathrm{Cr}$, and $\mathrm{Fn}$ ) were very high (98.7\% to $100 \%$ ), and $A$ a was detected in $73.7 \%$ of the patients. In a similar study, Brennan et al. ${ }^{33}$ determined the prevalence of infection with periodontal bacterial species in a sample of postmenopausal females. They found $T f$ in $37.9 \%$ of the samples and $\mathrm{Cr}, \mathrm{Pg}$, and $\mathrm{Fn}$ in $14 \%$ to $17 \%$. Disparities between study methods may account for the differences in their sensitivities with respect to the detection and quantification of periodontal pathogens. Brennan et al. ${ }^{33}$ used indirect immunofluorescence microscopy, which has important drawbacks compared with quantitative PCR, including a limited capability for accurate quantification and higher limits of detection. ${ }^{34}$

Macuch and Tanner ${ }^{35}$ identified $\mathrm{Cr}$ in $90 \%$ of their patients with newly diagnosed and established periodontitis, in $20 \%$ of those with gingivitis, and in $10 \%$ of those considered healthy. However, the samples in that study originated from a different source population than in the present study and relied on bacterial culturing methods, which have a lower sensitivity of detection. ${ }^{35}$

The sensitivity and specificity of qPCR are higher because this method overcomes most of the limitations of the other techniques. ${ }^{34,36,37}$ Therefore, the use of qPCR is one of the strengths of the present work. 
Table 5.

Spearman Correlation Coefficients $(r)$ and $P$ Values for all Pairs of Variables Shown.

\begin{tabular}{|c|c|c|c|c|c|c|c|c|c|}
\hline Variables & $\log P g$ & $\log T f$ & $\log C r$ & $\log F n$ & $\log A a$ & Age & Missing Teeth & CAOD Index & $\mathrm{pH}$ \\
\hline \multicolumn{10}{|l|}{ Log Pg } \\
\hline r & 1.000 & $0.410^{\dagger}$ & $0.328^{\dagger}$ & $0.268 *$ & 0.082 & -0.117 & -0.031 & -0.070 & 0.285 * \\
\hline$P$ & - & $<0.001$ & 0.004 & 0.02 & 0.55 & 0.32 & 0.79 & 0.56 & 0.02 \\
\hline \multicolumn{10}{|l|}{$\log T f$} \\
\hline r & $0.410^{\dagger}$ & 1.000 & $0.381^{\dagger}$ & $0.510^{\dagger}$ & $0.273^{*}$ & -0.162 & 0.022 & -0.031 & -0.056 \\
\hline P & $<0.001$ & - & 0.001 & $<0.001$ & 0.04 & 0.16 & 0.85 & 0.80 & 0.65 \\
\hline \multicolumn{10}{|l|}{$\log C r$} \\
\hline$r$ & $0.328^{\dagger}$ & $0.381^{\dagger}$ & 1.000 & $0.815^{\dagger}$ & 0.009 & -0.021 & 0.062 & 0.065 & 0.024 \\
\hline$P$ & 0.004 & 0.001 & - & $<0.001$ & 0.95 & 0.86 & 0.60 & 0.59 & 0.84 \\
\hline \multicolumn{10}{|l|}{ Log Fn } \\
\hline r & $0.268 *$ & $0.510^{\dagger}$ & $0.815^{\dagger}$ & 1.000 & 0.116 & -0.052 & 0.027 & -0.002 & -0.083 \\
\hline P & 0.02 & $<0.001$ & $<0.001$ & - & 0.40 & 0.66 & 0.82 & 0.98 & 0.50 \\
\hline \multicolumn{10}{|l|}{$\log A a$} \\
\hline$r$ & 0.082 & $0.273 *$ & 0.009 & 0.116 & 1.000 & -0.195 & 0.008 & 0.192 & -0.183 \\
\hline$P$ & 0.55 & 0.04 & 0.95 & 0.40 & - & 0.15 & 0.96 & 0.16 & 0.20 \\
\hline \multicolumn{10}{|l|}{ Age } \\
\hline r & -0.117 & -0.162 & -0.021 & -0.052 & -0.195 & 1.000 & 0.100 & 0.064 & -0.045 \\
\hline$P$ & 0.32 & 0.16 & 0.86 & 0.66 & 0.15 & - & 0.39 & 0.59 & 0.71 \\
\hline \multicolumn{10}{|c|}{ Missing teeth } \\
\hline$r$ & -0.031 & 0.022 & 0.062 & 0.027 & 0.008 & 0.100 & 1.000 & $0.770^{\dagger}$ & -0.041 \\
\hline$P$ & 0.79 & 0.85 & 0.60 & 0.82 & 0.96 & 0.39 & - & $<0.001$ & 0.74 \\
\hline \multicolumn{10}{|c|}{ CAOD index } \\
\hline$r$ & -0.070 & -0.031 & 0.065 & -0.002 & 0.192 & 0.064 & $0.770^{\dagger}$ & 1.000 & -0.059 \\
\hline$P$ & 0.56 & 0.79 & 0.59 & 0.98 & 0.16 & 0.59 & $<0.001$ & - & 0.63 \\
\hline \multicolumn{10}{|l|}{$\mathrm{pH}$} \\
\hline$r$ & $0.285^{*}$ & -0.056 & 0.024 & -0.083 & -0.183 & -0.045 & -0.041 & -0.059 & 1.000 \\
\hline P & 0.02 & 0.65 & 0.84 & 0.50 & 0.20 & $0.7 \mid$ & 0.74 & 0.63 & - \\
\hline
\end{tabular}

$P$ values in boldface are statistically significant.

* $P<0.05$.

$\dagger P<0.01$.

Riep et al. ${ }^{36}$ examined the prevalence of 10 periodontal bacterial species in three groups of patients, those with $\mathrm{CP}$ or generalized aggressive periodontitis and those in a periodontitis-resistant control group. PCR of 16S rRNA gene fragments and subsequent dot-blot hybridization were used as the detection method. The prevalence of $T f, P g$, and $P i$ was high in all groups ( $60 \%$ to $95 \%$ of positive patients), without significant differences among them, although these species are considered to be highly associated with advanced periodontitis. ${ }^{31}$ The prevalence of some of the target species in that study are similar to those detected in this study.

In examining the potential correlation between bacterial species, significant associations were found between $\mathrm{Fn}$ and $\mathrm{Cr}$, this will fit with the orange complex of Socransky et al., ${ }^{37} \mathrm{Fn}$ and $\mathrm{Tf}$, and $\mathrm{Pg}$ and $\mathrm{Tf}$ (red complex), among others. The simultaneous presence of these bacteria suggests their interdependence, which could further promote the progression of periodontal disease.

The lower presence of Aa detected in this study is correlated with an acidic oral environment. These results are in agreement with the observed optimal $\mathrm{pH}$ range for growth of this bacterium. ${ }^{38}$ The findings also suggest a greater abundance of $P g$ under acidic conditions ( $\mathrm{pH}$ below 7), although optimum $\mathrm{pH}$ for growth is close to neutrality. ${ }^{39}$ Maybe the association could be attributable to low salivary flow more than to $\mathrm{pH}$. This information could help clinicians choose the best approach for treating periodontal infections caused by these microorganisms.

The bacterial species investigated in this study do not show significant quantitative differences among 
healthy, osteopenic, and osteoporotic patients. The correlations between females with periodontitis and healthy patients were also negative. Therefore, the presence of subgingival periodontopathogenic bacteria in almost all of the present patients demonstrates that the appearance of these species is not sufficient to confirm the presence of periodontal disease. In fact, the mere presence of oral pathogens is recognized as being necessary but not sufficient for disease occurrence. Factors that influence disease development include the expression of virulence by the pathogen, the presence of interacting bacterial species, and the susceptibility of the individual host. ${ }^{28,40-42}$ Still, disease will not necessarily develop as long as the levels of the pathogen do not exceed the threshold for the host. ${ }^{38}$ In the present study, some of the healthy patients may have had early-stage, albeit, by the criteria of this study, non-detectable disease, which may have blunted any significant differences between patients with periodontitis and those who were apparently healthy.

\section{CONCLUSIONS}

In the present study, osteoporosis did not influence the prevalence of periodontitis among postmenopausal females. The presence of periodontopathogenic bacteria was not sufficient to confirm disease, although the influence of PD on the prevalence of the pathogens analyzed was not examined. Probably, the detection of these bacterial species may be more closely related to the depth of the sampled pocket than to the diagnosis of periodontitis, because deeper pockets offer a better environment for anaerobes and, consequently, their more extensive colonization. ${ }^{36,43}$ A preventive maintenance program for postmenopausal females, particularly osteoporotic females, who are at greater risk of tooth loss, could minimize the potential effects of bone loss on periodontal tissues. Additional studies are needed to examine the influence of confounding factors for periodontitis and osteoporosis in postmenopausal females.

\section{REFERENCES}

1. Al-Azzawi F, Palacios S. Hormonal changes during menopause. Maturitas 2009;63:135-137.

2. Ben Aryeh H, Gottlieb I, Ish-Shalom S, David A, Szargel $\mathrm{H}$, Laufer D. Oral complaints related to menopause. Maturitas 1996;24:185-189.

3. Marcotte H, Lavoie MC. Oral microbial ecology and the role of salivary immunoglobulin A. Microbiol Mol Biol Rev 1998;62:71-109.

4. Saluja P, Shetty V, Dave A, Arora M, Hans V, Madan A. Comparative evaluation of the effect of menstruation, pregnancy and menopause on salivary flow rate, $\mathrm{pH}$ and gustatory function. J Clin Diagn Res 2014;8:ZC81-ZC85.

5. Krejci CB, Bissada NF. Women's health issues and their relationship to periodontitis. J Am Dent Assoc 2002; 133:323-329.
6. Darcey J, Devlin H, Lai D, et al. An observational study to assess the association between osteoporosis and periodontal disease. Br Dent J 2013;215:617-621.

7. Edwards BJ, Li J. Endocrinology of menopause. Periodontol 2000 2013;61:177-194.

8. López-López J, Castellanos-Cosano L, Estrugo-Devesa A, Gómez-Vaquero C, Velasco-Ortega E, Segura-Egea JJ. Radiolucent periapical lesions and bone mineral density in post-menopausal women. Gerodontology 2015; 32:195-201.

9. National Institute of Arthritis and Musculoskeletal and Skin Diseases. NIH osteoporosis and related bone diseases-National Resource Center. Oral health and bone disease, January 1-2, 2012. Available at: www. niams.nih.gov. Accessed March 8, 2015.

10. Pepelassi E, Nicopoulou-Karayianni K, Archontopoulou AD, et al. The relationship between osteoporosis and periodontitis in women aged $45-70$ years. Oral Dis 2012; 18:353-359.

11. Herrera D, Contreras A, Gamonal J, et al. Subgingival microbial profiles in chronic periodontitis patients from Chile, Colombia and Spain. J Clin Periodontol 2008;35: 106-113.

12. Mineoka T, Awano S, Rikimaru T, et al. Site-specific development of periodontal disease is associated with increased levels of Porphyromonas gingivalis, Treponema denticola, and Tannerella forsythia in subgingival plaque. J Periodontol 2008;79:670-676.

13. Greene JC, Vermillion JR. The simplified oral hygiene index. J Am Dent Assoc 1964;68:7-13.

14. WHO Study Group. Assessment of fracture risk and its application to screening for postmenopausal osteoporosis. Report of a World Health Organization technical report series. Geneva, Switzerland; 1994;843:1-129.

15. Jeffcoat $M$. The association between osteoporosis and oral bone loss. J Periodontol 2005;76(Suppl. 11): 2125-2132.

16. Estrugo-Devesa A, Gómez-Vaquero C, López-López J. Osteoporosis and oral diseases (in Spanish). Med Clin (Barc) 2013;140:169-174.

17. Armitage GC. Development of a classification system for periodontal diseases and conditions. Ann Periodontol 1999;4:1-6.

18. Boutaga K, Van Winkelhoff AJ, Vandenbroucke-Grauls CM, Savelkoul PH. Comparison of real-time PCR and culture for detection of porphyromonas gingivalis in subgingival plaque samples. J Clin Microbiol 2003;41: 4950-4954.

19. Figuero E, Lindahl C, Marín MJ, et al. Quantification of periodontal pathogens in vascular, blood and subgingival samples from patients with peripheral arterial disease or abdominal aortic aneurysms. J Periodontol 2014;85: 1182-1193.

20. Martínez-Maestre MÁ, González-Cejudo C, Machuca G, Torrejón R, Castelo-Branco C. Periodontitis and osteoporosis: A systematic review. Climacteric 2010;13:523-529.

21. Moeintaghavi A, Pourjavad M, Dadgar S, Tabbakh NS. Evaluation of the association between periodontal parameters, osteoporosis and osteopenia in post menopausal women. J Dent (Tehran) 2013;10:443-448.

22. Passos JS, Vianna MIP, Gomes-Filho IS, et al. Osteoporosis/ osteopenia as an independent factor associated with periodontitis in postmenopausal women: A case-control study. Osteoporos Int 2013;24:1275-1283.

23. Krall EA, Dawson-Hughes B, Papas A, Garcia RI. Tooth loss and skeletal bone density in healthy postmenopausal women. Osteoporos Int 1994;4:104-109. 
24. Machtei EE, Hausmann E, Dunford R, et al. Longitudinal study of predictive factors for periodontal disease and tooth loss. J Clin Periodontol 1999;26:374-380.

25. Tezal M, Wactawski-Wende J, Grossi SG, Dmochowski $\mathrm{J}$, Genco RJ. Periodontal disease and the incidence of tooth loss in postmenopausal women. $J$ Periodontol 2005;76:1123-1128.

26. Chambrone LA, Chambrone L. Tooth loss in wellmaintained patients with chronic periodontitis during long-term supportive therapy in Brazil. J Clin Periodontol 2006;33:759-764.

27. Matuliene G, Studer R, Lang NP, et al. Significance of periodontal risk assessment in the recurrence of periodontitis and tooth loss. J Clin Periodontol 2010;37:191 199.

28. Renvert S, Persson RE, Persson GR. Tooth loss and periodontitis in older individuals: Results from the Swedish National Study on Aging and Care. JPeriodontol2013;84: 1134-1144.

29. Meisel P, Kroemer HK, Nauck M, Holtfreter B, Kocher T. Tooth loss, periodontitis, and statins in a population-based follow-up study. J Periodontol 2014;85:e160-e168.

30. Buchwald S, Kocher T, Biffar R, Harb A, Holtfreter B, Meisel P. Tooth loss and periodontitis by socio-economic status and inflammation in a longitudinal populationbased study. J Clin Periodontol 2013;40:203-211.

31. Mahesh DR, Komali G, Jayanthi K, Dinesh D, Saikavitha TV, Dinesh P. Evaluation of salivary flow rate, $\mathrm{pH}$ and buffer in pre, post \& post menopausal women on HRT. J Clin Diagn Res 2014;8:233-236.

32. Eliasson L, Carlén A, Laine M, Birkhed D. Minor gland and whole saliva in postmenopausal women using a low potency oestrogen (oestriol). Arch Oral Biol 2003;48:511-517.

33. Brennan RM, Genco RJ, Wilding GE, Hovey KM, Trevisan M, Wactawski-Wende J. Bacterial species in subgingival plaque and oral bone loss in postmenopausal women. J Periodontol 2007;78:1051-1061.

34. Sanz M, Lau L, Herrera D, Morillo JM, Silva A. Methods of detection of Actinobacillus actinomycetemcomitans, Porphyromonas gingivalis and Tannerella forsythensis in periodontal microbiology, with special emphasis on advanced molecular techniques: A review. J Clin Periodontol 2004;31:1034-1047.

35. Macuch PJ, Tanner AC. Campylobacter species in health, gingivitis, and periodontitis. J Dent Res 2000;79:785-792.

36. Riep B, Edesi-Neuss L, Claessen F, et al. Are putative periodontal pathogens reliable diagnostic markers? $J$ Clin Microbiol 2009;47:1705-1711.

37. Socransky SS, Haffajee AD, Cugini MA, Smith C, Kent RL Jr. Microbial complexes in subgingival plaque. $J$ Clin Periodontol 1998;25:134-144.

38. Jervøe-Storm PM, Koltzscher M, Falk W, Dörfler A, Jepsen S. Comparison of culture and real-time PCR for detection and quantification of five putative periodontopathogenic bacteria in subgingival plaque samples. $J$ Clin Periodontol 2005;32:778-783.

39. Bhattacharjee MK, Childs CB, Ali E. Sensitivity of the periodontal pathogen Aggregatibacter actinomycetemcomitans at mildly acidic pH. J Periodontol 2011;82: 917-925.

40. Takahashi $\mathrm{N}$, Schachtele CF. Effect of $\mathrm{pH}$ on the growth and proteolytic activity of Porphyromonas gingivalis and Bacteroides intermedius. JDent Res 1990;69:1266-1269.

41. Mombelli A, Casagni F, Madianos PN. Can presence or absence of periodontal pathogens distinguish between subjects with chronic and aggressive periodontitis? A systematic review. J Clin Periodontol 2002;29(Suppl. 3):10-21, discussion 37-38.

42. Socransky SS, Haffajee AD. The bacterial etiology of destructive periodontal disease: Current concepts. $J$ Periodontol 1992;63(Suppl. 4):322-331.

43. Umeda M, Chen C, Bakker I, Contreras A, Morrison JL, Slots J. Risk indicators for harboring periodontal pathogens. J Periodontol 1998;69:1111-1118.

Correspondence: Dr. Blanca Martínez-Garriga, Laboratory of Molecular Microbiology, Faculty of Medicine, University of Barcelona, Feixa Llarga s/n, 08907 Hospitalet de Llobregat, Spain. E-mail: mvinyas@ub.edu.

Submitted June 16, 2015; accepted for publication September 9, 2015. 